\title{
Analytical and numerical studies on heat transfer of a nanofluid over a stretching/ shrinking sheet with second-order slip flow model
}

\author{
M. M. Rashidi ${ }^{1,2}$, A. K. Abdul Hakeem ${ }^{3}$, N. Vishnu Ganesh ${ }^{3}$, B. Ganga ${ }^{4}$, M. Sheikholeslami ${ }^{5}$ and E. Momoniat ${ }^{6^{*}}$ (D)
}

\begin{abstract}
Background: The objective of the present study is to analyse the steady second-order slip flow and heat transfer of an incompressible viscous water-based nanofluid over a stretching/shrinking sheet both analytically and numerically.

Methods: Using the scaling group transformations, a system of partial differential equations governing the flow and thermal fields is transformed into a system of ordinary differential equations. An exact solution to the momentum equation is obtained, and the solution of the energy equation is obtained in terms of a hypergeometric function for different water-based nanofluids containing $\mathrm{Au}, \mathrm{Ag}, \mathrm{Cu}, \mathrm{Al}_{1} \mathrm{Al}^{2} \mathrm{O}^{3}$ and $\mathrm{TiO}^{2}$ nanoparticles. Numerical solutions are obtained using a fourth-order Runge-Kutta method coupled with a shooting iteration technique.

Results: It is found that there exist a unique solution in the case of a stretching sheet with suction, but there is no solution in both stretching and shrinking sheets with injection. Dual solutions are obtained in a shrinking sheet beyond a suction critical point. The presence of nanoparticles decreases the suction critical point.

Conclusions: Excellent agreement is observed between the analytical and numerical results. The effects of important physical parameters are analysed in detail. The corresponding local skin-friction coefficient and the reduced Nusselt number are also calculated and displayed in tables.
\end{abstract}

Keywords: Second-order slip, Heat transfer, Nanofluid, Scaling group transformations, Stretching/shrinking sheet

\section{Background}

Boundary-layer flow over a continuously stretching/ shrinking surface has many important applications in engineering processes. Some of these applications include polymer extrusion, drawing of plastic films and wires, glass fibre and paper production, manufacture of foods, crystal growing, liquid films in condensation process, etc. The flow induced by a moving boundary is important in extrusion processes. The permeable stretching/shrinking sheet is one such example, which has been studied with no slip regime or slip regime at the surface. Pioneering work in this area was conducted by Sakiadis

\footnotetext{
* Correspondence: Ebrahim.Momoniat@wits.ac.za

${ }^{6}$ DST/NRF Centre of Excellence in the Mathematical and Statistical Sciences, School of Computer Science and Applied Mathematics, University of the Witwatersrand, Private Bag 3, Johannesburg, Wits 2050, South Africa Full list of author information is available at the end of the article
}

(1961a, b, c). Sakiadis analysed the boundary-layer assumptions and the governing equations of boundary-layer flow on a surface that is continuously stretching with a constant speed. When the fluid is particulate such as emulsions, suspensions, foams and polymer solutions, the no slip condition is inadequate. The problem of flow and heat transfer over a stretching/shrinking surface with slip regime has been investigated and discussed by many researchers (Wang 2009; Sahoo 2010; Miklavcic and Wang 2006; Fang, Zhang and Yao 2010; Abdul Hakeem et al. 2014).

The slip velocity for rarefied gases flowing over a solid surface is the Maxwell (1879) slip condition and is widely implemented in current rarefied gas flow investigations. Based on Maxwell's first-order slip model, Thompson developed a second-order slip model, but many researchers reported that Thompson's model cannot predict the flow in high Knudsen number (Kn). Beskok and Karniadakis (1999) suggested an
Springer

(c) 2016 Rashidi et al. Open Access This article is distributed under the terms of the Creative Commons Attribution 4.0 International License (http://creativecommons.org/licenses/by/4.0/), which permits unrestricted use, distribution, and reproduction in any medium, provided you give appropriate credit to the original author(s) and the source, provide a link to the Creative Commons license, and indicate if changes were made. 
improved second-order slip condition. For more details, readers are encouraged to read the papers by Srikanth (1969) and Wu (2008). Recently, Fang et al. (2010) considered the effects of the second-order slip on the flow of a shrinking sheet. The case of a stretching sheet was studied by Nandeppanavar et al. (2012). Turkyilmazoglu (2013) analysed the second-order slip flow and heat transfer over a stretching/shrinking sheet with magnetic field effect.

Nanofluids or so-called smart fluids research have attracted considerable attention in recent years owing to their significant applications in engineering and technology. The broad range of current and future applications involving nanofluids has been given in the publications (Das et al. 2007; Wang and Mujumdar 2008a, b; Sheremet et al. 2015; Sheremet and Pop 2014; Zaimi et al. 2014). Many recent studies on boundary-layer flow in nanofluids have been undertaken with the absence of slip effects (Khan and Pop 2010; Kuznetsov and Nield 2010; Gorder et al. 2010; Akyildiz et al. 2011; Hamad 2011; Rashidi and Erfani 2011; Vajravelu et al. 2011; Rashidi, Freidoonimehr et al. 2013; Vishnu Ganesh, Ganga and Abdul Hakeem 2014; Vishnu Ganesh, Abdul Hakeem et al. 2014; Govindaraju et al. 2014; Ganga et al. 2014; Rashidi,Freidoonimehr, N, Hosseini, A et al. 2013; Sheikholeslami and Ganji 2014; Hatami et al. 2014; Rashidi, Vishnu Ganesh et al. 2014; Rashidi, Momoniat et al. 2014; Garoosi et al. 2015; Freidoonimehr and Rashidi 2015). Das (2012) obtained a numerical solution for convective heat transfer performance of nanofluids over a permeable stretching surface in the presence of a partial slip, thermal buoyancy and temperature-dependent internal heat generation or absorption. Turkyilmazoglu (2012) investigated the behaviour of fluid flow and thermal transport of some electrically conducting nanofluid over a permeable stretching/shrinking sheet for the nanoparticles $\mathrm{Cu}, \mathrm{Ag}$, $\mathrm{CuO}, \mathrm{Al}_{2} \mathrm{O}_{3}$ and $\mathrm{TiO}_{2}$ with basic slip conditions. Noghrehabad and Pourrajab (2012) analysed the effect of a partial slip boundary condition on the flow and heat transfer of nanofluids past a stretching sheet for prescribed constant wall temperature. More recently, Ibrahim and Shankar (2013) studied the partial slip (first-order slip) and thermal slip effects on MHD boundary-layer flow and heat transfer of a nanofluid past a permeable stretching sheet.

Bearing this in mind, we analyse the steady laminar flow and heat transfer of an incompressible, viscous, water-based nanofluid over a stretching/shrinking sheet with secondorder slip for different nanoparticles such as $\mathrm{Au}, \mathrm{Ag}, \mathrm{Cu}, \mathrm{Al}$, $\mathrm{Al}_{2} \mathrm{O}_{3}$ and $\mathrm{TiO}_{2}$ both analytically and numerically.

The paper is divided up as follows: in section Formulation of the Problem, we derive a system of nonlinear partial differential equations modelling boundary-layer flow on a stretching/shrinking sheet with second-order slip. In section Solution for the Flow Field, we use a similarity transformation to reduce the system of partial differential equations to a system of ordinary differential equations. Analytical solutions for the velocity components are obtained in this section. An exact solution in terms of a hypergeometric function is obtained for the energy equation in section Solution for the Thermal Transport. Numerical solutions for the system are determined in section Numerical Method for Solution. Results are discussed in section Results and Discussion, and concluding remarks are made in section Conclusions.

\section{Formulation of the problem}

Consider the steady, two-dimensional laminar slip flow of an incompressible viscous water-based nanofluid over a continuously stretching or shrinking sheet coinciding with the plane $\bar{y}=0$, the flow being confined to $\bar{y}>0$ (see Fig. 1). The temperature at the stretching/shrinking surface takes the constant value $T_{w}$, while the ambient value, attained as $\bar{y}$, tends to infinity and takes the constant value $T_{\infty}$. The fluid is assumed to be a water-based nanofluid containing different types of nanoparticles: gold $(\mathrm{Au})$, copper $(\mathrm{Cu})$, silver $(\mathrm{Ag})$, aluminium $(\mathrm{Al})$, aluminium oxide $\left(\mathrm{Al}_{2} \mathrm{O}_{3}\right)$ and titanium oxide $\left(\mathrm{TiO}_{2}\right)$. It is also assumed that the base fluid and the nanoparticles are in thermal equilibrium and no slip occurs between them. The thermo physical properties of the nanofluid are considered as given in Table 1. Under the above assumptions, the boundary-layer equations governing the flow and thermal fields can be written in dimensional form as

$$
\begin{aligned}
& \frac{\partial \bar{u}}{\partial \bar{x}}+\frac{\partial \bar{v}}{\partial \bar{y}}=0, \\
& \bar{u} \frac{\partial \bar{u}}{\partial \bar{x}}+\bar{v} \frac{\partial \bar{u}}{\partial \bar{y}}=\left(\frac{\mu_{n f}}{\rho_{n f}}\right) \frac{\partial^{2} \bar{u}}{\partial \bar{y}^{2}}, \\
& \bar{u} \frac{\partial T}{\partial \bar{x}}+\bar{v} \frac{\partial T}{\partial \bar{y}}=\alpha_{n f} \frac{\partial^{2} T}{\partial \bar{y}^{2}},
\end{aligned}
$$

where $\bar{x}$ is the coordinate along the sheet, $\bar{u}$ is the velocity component in the $\bar{x}$ direction, $\bar{y}$ is the coordinate perpendicular to the sheet, $\bar{v}$ is the velocity component in the $\bar{y}$ direction, $T$ is the local temperature of the fluid, $\alpha_{n f}=\frac{k_{n f}}{\left(\rho C_{p}\right)_{n f}}$ is the thermal diffusivity of the nanofluid, $\rho_{n f}$ is the effective density of the nanofluid, $\mu_{n f}$ is the effective dynamic viscosity of the nanofluid and $\left(\rho C_{p}\right)_{n f}$ is the heat capacitance and $k_{n f}$ is the thermal conductivity of the nanofluid are given as 


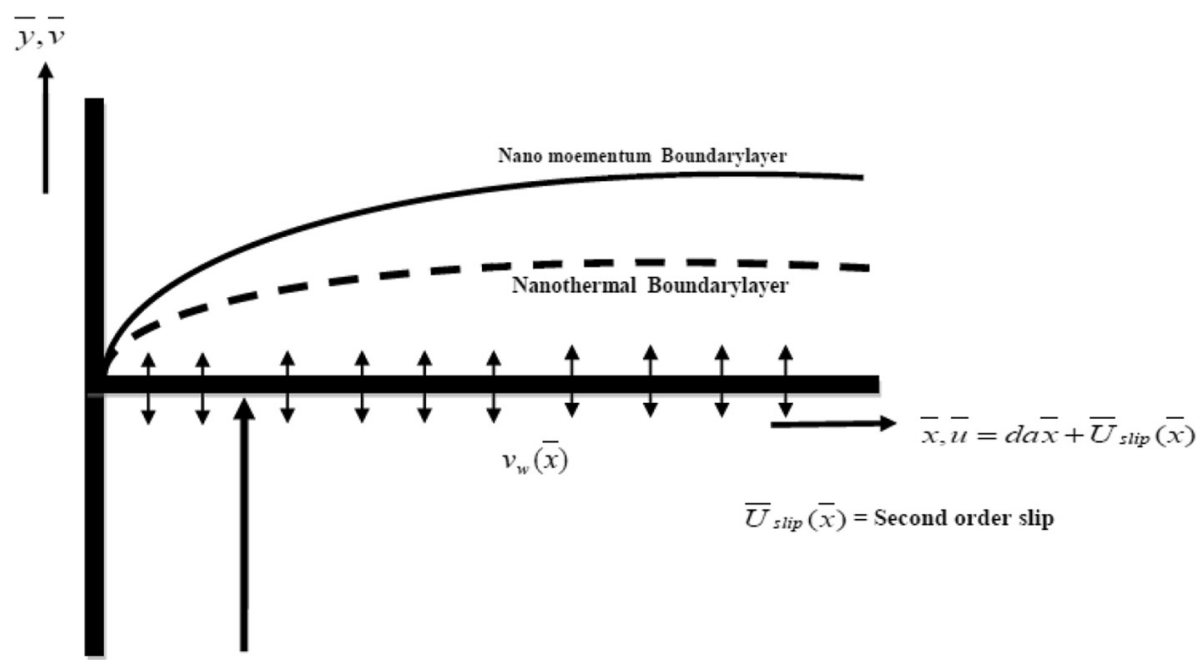

Stretching/ shrinking sheet

Fig. 1 Schematic diagram of boundary-layer flow over a stretching sheet

$$
\begin{gathered}
\rho_{n f}=(1-\phi) \rho_{f}+\phi \rho_{s}, \quad \mu_{n f}=\frac{\mu_{f}}{(1-\phi)^{2.5}}, \\
\left(\rho C_{p}\right)_{n f}=(1-\phi)\left(\rho C_{p}\right)_{f}+\phi\left(\rho C_{p}\right)_{s}, \\
k_{n f}=k_{f}\left\{\frac{k_{s}+2 k_{f}-2 \phi\left(k_{f}-k_{s}\right)}{k_{s}+2 k_{f}+\phi\left(k_{f}-k_{s}\right)}\right\} .
\end{gathered}
$$

Here, $\phi$ is the solid volume fraction. The boundary conditions are given by

$$
\begin{aligned}
& \bar{u}=d c \bar{x}+\bar{U}_{\text {slip },} \quad \bar{v}=\bar{v}_{w}(\bar{x}), \quad T=T_{w} \quad \text { at } \quad \bar{y}=0, \\
& \bar{u} \rightarrow 0, \quad T \rightarrow T_{\infty} \text { as } \quad \bar{y} \rightarrow \infty,
\end{aligned}
$$

where $d=1$ denotes stretching and $d=-1$ denotes shrinking sheets, respectively. Parameter $c$ is a constant and $\bar{U}_{\text {slip }}$ is the slip velocity at the wall; $v_{w}$ is the wall mass transfer velocity. The slip velocity model (valid for

Table 1 Thermo-physical properties of water and nano particles (Domkundwar and Domdundwar 2004)

\begin{tabular}{llll}
\hline & $\rho\left(\mathrm{kg} / \mathrm{m}^{3}\right)$ & $\mathrm{C}_{p}(\mathrm{~J} / \mathrm{kg} \mathrm{K})$ & $\mathrm{k}(\mathrm{W} / \mathrm{m} \mathrm{K})$ \\
\hline Pure water & 997.1 & 4179 & 0.613 \\
Gold $(\mathrm{Au})$ & 19,300 & 132 & 296 \\
Silver $(\mathrm{Ag})$ & 10,500 & 235 & 429 \\
Copper (Cu) & 8933 & 385 & 401 \\
Aluminium (Al) & 2710 & 913 & 201 \\
Aluminium oxide $\left(\mathrm{Al}_{2} \mathrm{O}_{3}\right)$ & 3970 & 765 & 40 \\
Titanium oxide $\left(\mathrm{TiO}_{2}\right)$ & 4250 & 686.2 & 8.9538 \\
\hline
\end{tabular}

arbitrary Knudsen numbers, $K_{n}$ ) (Nandeppanavar et al. 2012) is given by

$$
\begin{aligned}
\bar{U}_{\text {slip }} & =\frac{2}{3}\left(\frac{3-\alpha l^{3}}{\alpha}-\frac{31-l^{2}}{2}\right) \lambda \frac{\partial \bar{u}}{\partial \bar{y}}-\frac{1}{4}\left[I^{4}+\frac{2}{K_{n}^{2}}\left(1-l^{2}\right)\right] \lambda^{2} \frac{\partial^{2} \bar{u}}{\partial \bar{y}^{2}} \\
& =A \frac{\partial \bar{u}}{\partial \bar{y}}+B \frac{\partial^{2} \bar{u}}{\partial \bar{y}^{2}}
\end{aligned}
$$

where $I=\min \left[1 / K_{n}, 1\right], \alpha$ is the momentum accommodation coefficient with $0 \leq \alpha \leq 1$ and $\lambda$ is the molecular mean free path. Based on the definition of $l$, it is noticed that for any given value of $K_{n}$, we have $0 \leq 1 \leq 1$. The molecular mean free path is always positive. Thus, we know that $B<0$, and hence, the second term in right hand side of Eq. 5 is a positive number.

There are several applications that involve microscale devices including heat exchangers, micro-power system and sensor. The gas flow in micro channels classified into four flow regimes based on Knudsen $\left(K_{n}\right)$ number (Beskok and Karniadakis 1994) as: (1) continuum flow regime $\left(K_{n} \leq 0.001\right)$, (2) slip flow regime $\left(0.001 \leq K_{n} \leq 0.1\right)$, (3) transition flow regime $\left(0.1 \leq K_{n} \leq 10\right)$ and (4) free molecular flow regime $\left(K_{n}>10\right)$. The Navier-Stokes equations are first-order accurate in $K_{n}$ number increases; so, most researchers insisted that the Navier-Stokes equations cannot govern slip flow in transition region with a second-order or higher-order slip model.

By introducing the stream function $\psi$, which is defined as $u=\frac{\partial \psi}{\partial y}, v=-\frac{\partial \psi}{\partial x}$ and the following non-dimensional variables 


$$
\begin{aligned}
& x=\frac{\bar{x}}{\sqrt{\frac{v_{f}}{c}}}, \quad y=\frac{\bar{y}}{\sqrt{\frac{v_{f}}{c}}}, \quad u=\frac{\bar{u}}{\sqrt{v_{f} c}}, \quad v=\frac{\bar{v}}{\sqrt{v_{f} c}}, \\
& \theta=\frac{T-T_{\infty}}{T_{w}-T_{\infty}},
\end{aligned}
$$

Equations 1-3 take the following form

$$
\begin{aligned}
& \frac{\partial^{2} \psi}{\partial x \partial y}-\frac{\partial^{2} \psi}{\partial y \partial x}=0 \\
& \frac{\partial \psi}{\partial y} \frac{\partial^{2} \psi}{\partial x \partial y}-\frac{\partial \psi}{\partial x} \frac{\partial^{2} \psi}{\partial y^{2}}=\frac{1}{\left(1-\phi+\phi \frac{\rho_{s}}{\rho_{f}}\right)}\left\{\frac{1}{(1-\phi)^{2.5}} \frac{\partial^{3} \psi}{\partial y^{3}}\right\} \\
& \frac{\partial \psi}{\partial y} \frac{\partial \theta}{\partial x}-\frac{\partial \psi}{\partial x} \frac{\partial \theta}{\partial y}=\left(\frac{k_{n f}}{k_{f} \operatorname{Pr}}\right) \frac{1}{(1-\phi)+\phi \frac{\left(\rho C_{p}\right)_{s}}{\left(\rho C_{p}\right)_{f}} \frac{\partial^{2} \theta}{\partial y^{2}}}
\end{aligned}
$$

where the boundary conditions in Eq. 4 become

$$
\begin{aligned}
\frac{\partial \psi}{\partial y} & =d x+\gamma \frac{\partial^{2} \psi}{\partial y^{2}}+\delta \frac{\partial^{3} \psi}{\partial y^{3}}, \quad \frac{\partial \psi}{\partial x}=s, \quad \theta=1 \quad \text { at } \\
y & =0, \frac{\partial \psi}{\partial y} \rightarrow 0, \quad \theta \rightarrow 0 \quad \text { as } \quad y \rightarrow \infty,
\end{aligned}
$$

where $\rho_{f}$ is the density of the pure fluid, $\left(\rho C_{p}\right)_{f}$ is the specific heat parameter of the base fluid, $k_{f}$ is the thermal conductivity of the base fluid, $\rho_{s}$ is the density of the nanoparticles, $\left(\rho C_{p}\right)_{s}$ is the specific heat parameter of the nanoparticles, $k_{s}$ is the thermal conductivity of the nanoparticles, $\operatorname{Pr}=\frac{v_{f}}{\alpha_{f}}$ is the Prandtl number, $\gamma$ is the first-order velocity slip parameter with $0<\gamma=A \sqrt{c / v_{f}}$ and $\delta$ is the secondorder velocity slip parameter with $0>\delta=B c / v_{f}$.

Now, using the scaling group $\mathrm{G}$ of transformations,

\begin{tabular}{|c|c|c|c|c|}
\hline \multirow[t]{2}{*}{ y } & \multirow[t]{2}{*}{$\delta$} & \multicolumn{2}{|c|}{ Present results with $\varphi=0, d=1$ and $s=2$} & \multirow{2}{*}{$\begin{array}{l}\text { Turkyilmazoglu (2013) } \\
\text { with } M=0\end{array}$} \\
\hline & & Analytical & Numerical & \\
\hline 1 & -1 & 0.281688 & 0.2816883004 & 0.28168830 \\
\hline 3 & -3 & 0.104492 & 0.1044918663 & 0.10449187 \\
\hline 5 & -5 & 0.064205 & 0.0642051113 & 0.06420511 \\
\hline
\end{tabular}
we get the scaling transformations as stated in (Hamad 2011; Vishnu Ganesh, Ganga and Abdul Hakeem 2014)

$$
\eta=y, \quad \psi=x F(\eta), \quad \theta=\theta(\eta) .
$$

Table 2 Comparison of $-F^{\prime \prime}(0)$ for stretching sheet
Table 3 Comparison of upper and lower branch of $\beta$ for $d=-1$, $\varphi=0$ and $\delta=-1$

\begin{tabular}{lllll}
\hline$s$ & $\gamma$ & \multicolumn{2}{c}{ Present results } & \multirow{2}{*}{$\begin{array}{l}\text { Turkyilmazoglu } \\
\text { (2013) } \beta\end{array}$} \\
\cline { 3 - 4 } & & Analytical & Numerical & \\
\hline $2^{U}$ & 1 & 1.921290 & 1.9212896099 & 1.9212896 \\
$3^{U}$ & 3 & 2.982202 & 2.9822016783 & 2.9822017 \\
$2^{L}$ & 1 & 0.400529 & 0.4005289858 & 0.40052899 \\
$3^{L}$ & 3 & 0.213017 & 0.2130166962 & 0.21301670 \\
\hline
\end{tabular}

Solution for the flow field

Now, substituting the similarity transformations (11) in Eq. 8, we get

$$
F^{\prime \prime \prime}+(1-\phi)^{2.5}\left[1-\phi+\phi \frac{\rho_{s}}{\rho_{f}}\right]\left(F F^{\prime \prime}-F^{\prime 2}\right)=0,
$$

and the corresponding boundary conditions are

$$
\begin{aligned}
& F=s, \quad F^{\prime}=d+\gamma F^{\prime \prime}+\delta F^{\prime \prime \prime} \quad \text { at } \quad \eta=0, \\
& F^{\prime} \rightarrow 0 \quad \text { as } \eta \rightarrow \infty,
\end{aligned}
$$

where the primes denote the differentiation with respect to $\eta$.

The exact solution to the differential Eq. 12 satisfying the boundary conditions (13) is obtained as

$$
F(\eta)=s+\frac{d\left(1-e^{-\beta \eta}\right)}{\beta\left(1+\gamma \beta-\delta \beta^{2}\right)},
$$

substituting Eq. 14 in Eq. 12 gives the following fourth-order algebraic equation for the characteristic parameter $\beta$

$$
\begin{aligned}
& d(1-\phi)^{2.5}\left[1-\phi+\phi \frac{s}{f}\right]-\left(s(1-\phi)^{2.5}\left[1-+\frac{s}{f}\right]-\beta\right) \\
& \beta\left(\delta \beta^{2}-\gamma \beta-1\right)=0 .
\end{aligned}
$$

The velocity profile for both the stretching and shrinking surface is obtained as

$$
F^{\prime}(\eta)=\frac{d e^{-\beta \eta}}{\left(1+\gamma \beta-\delta \beta^{2}\right)},
$$

The corresponding four roots of Eq. 15 are analytically expressed as

Table 4 Comparison of $-\theta^{\prime}(0)$ with $d=1, s=0, \gamma=0, \delta=0$ and $\varphi=0$

\begin{tabular}{llll}
\hline $\operatorname{Pr}$ & Present results & & Wang \\
\cline { 2 - 3 } & Analytical & Numerical & (1989) \\
\hline 0.07 & 0.065563 & 0.0655624591 & 0.0656 \\
0.2 & 0.169089 & 0.1690885734 & 0.1691 \\
\hline
\end{tabular}

$\mathrm{U}$ denotes upper branch solutions and $\mathrm{L}$ denotes lower branch solutions 


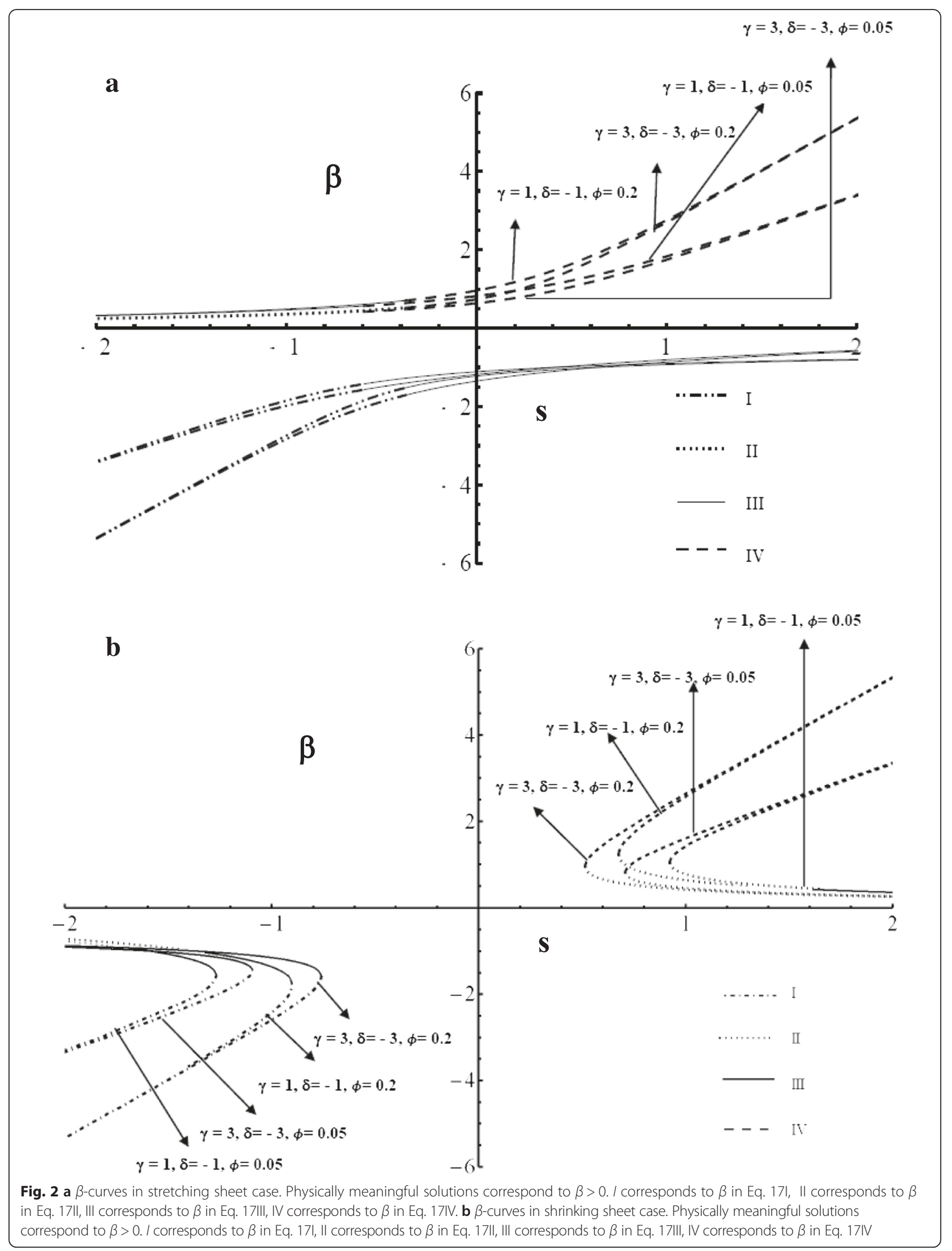




$$
\begin{aligned}
& \beta=-\frac{-\gamma-C s \delta}{4 \delta}-\frac{\beta_{4}}{2}-\frac{\sqrt{\beta_{6}-\beta_{7}}}{2}, \\
& \beta=-\frac{-\gamma-C s \delta}{4 \delta}-\frac{\beta_{4}}{2}+\frac{\sqrt{\beta_{6}-\beta_{7}}}{2}, \\
& \beta=-\frac{-\gamma-C s \delta}{4 \delta}+\frac{\beta_{4}}{2}-\frac{\sqrt{\beta_{6}+\beta_{7}}}{2}, \\
& \beta=-\frac{-\gamma-C s \delta}{4 \delta}+\frac{\beta_{4}}{2}+\frac{\sqrt{\beta_{6}+\beta_{7}}}{2},
\end{aligned}
$$

where

$$
\begin{aligned}
\beta_{1}= & 2^{1 / 3}\left(12(C d) \delta+(-1+C s \gamma)^{2}-3(C s)(-\gamma-C s \delta)\right), \\
\beta_{2}= & 27(C s)^{2} \delta-72(C d) \delta(-1+C s \gamma)+2(-1+C s \gamma)^{3} \\
& -9(C s)(-1+C s \gamma)(-\gamma-C s \delta)+27(C d)(-\gamma-C s \delta)^{2}, \\
\beta_{3}= & \left(\beta_{2}+\sqrt{-4\left(\frac{\beta_{1}}{2^{1 / 3}}\right)^{3}+\beta_{2}^{2}}\right)^{1 / 3}, \\
\beta_{4}= & \sqrt{\frac{-2(-1+C s \gamma)}{3 \delta}+\frac{(-\gamma-C s \delta)^{2}}{4 \delta^{2}}+\frac{\beta_{1}}{3 \delta \beta_{3}}+\frac{\beta_{3}}{3 \delta 2^{1 / 3}}}, \\
\beta_{5}= & \frac{-8(C s)}{\delta}+\frac{4(-1+C s \gamma)(-\gamma-C s \delta)}{\delta^{2}}-\frac{(-\gamma-C s \delta)^{3}}{\delta^{3}}, \\
\beta_{6}= & \frac{-4(-1+C s \gamma)}{3 \delta}+\frac{(-\gamma-C s \delta)^{2}}{2 \delta^{2}}-\frac{\beta_{1}}{3 \delta \beta_{3}}-\frac{\beta_{3}}{3 \delta 2^{1 / 3}},
\end{aligned}
$$

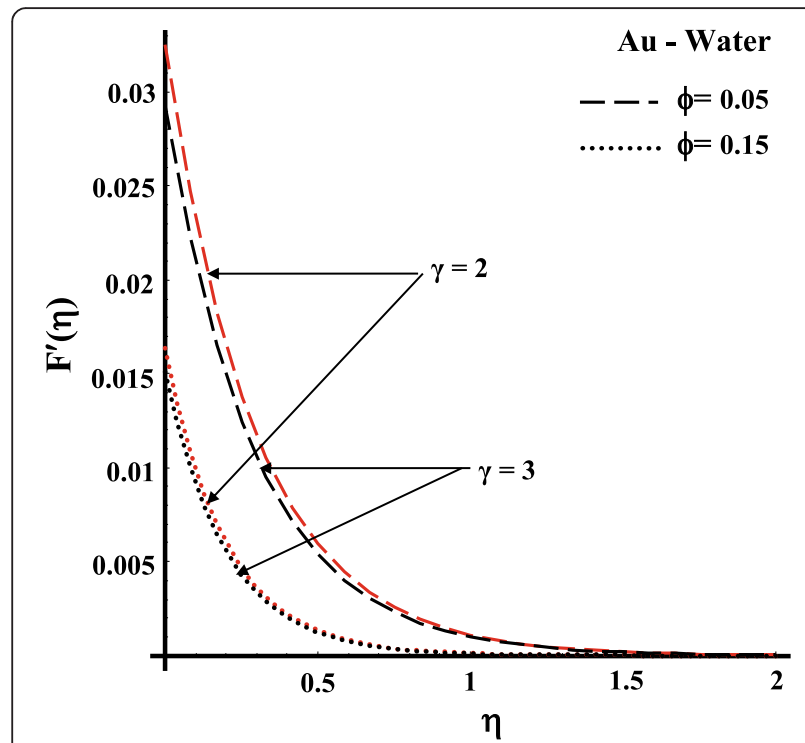

Fig. 3 Effects of first-order slip parameter and nanoparticle volume fraction parameter on $F^{\prime}(\eta)$ with $s=2, d=1$ and $\delta=-2$ for stretching sheet

$$
\beta_{7}=\frac{\beta_{5}}{4 \beta_{4}}, \quad \text { and } \quad C=(1-\phi)^{2.5}\left[1-\phi+\phi \frac{\rho_{s}}{\rho_{f}}\right] .
$$

The non-dimensional velocity components are given by

$$
u=x \frac{d e^{-\beta \eta}}{\left(1+\beta \gamma-\delta \beta^{2}\right)}, \quad v=-\left(s+\frac{d\left(1-e^{-\beta \eta}\right)}{\beta\left(1+\beta \gamma-\delta \beta^{2}\right)}\right) .
$$

The dimensional velocity components are given by

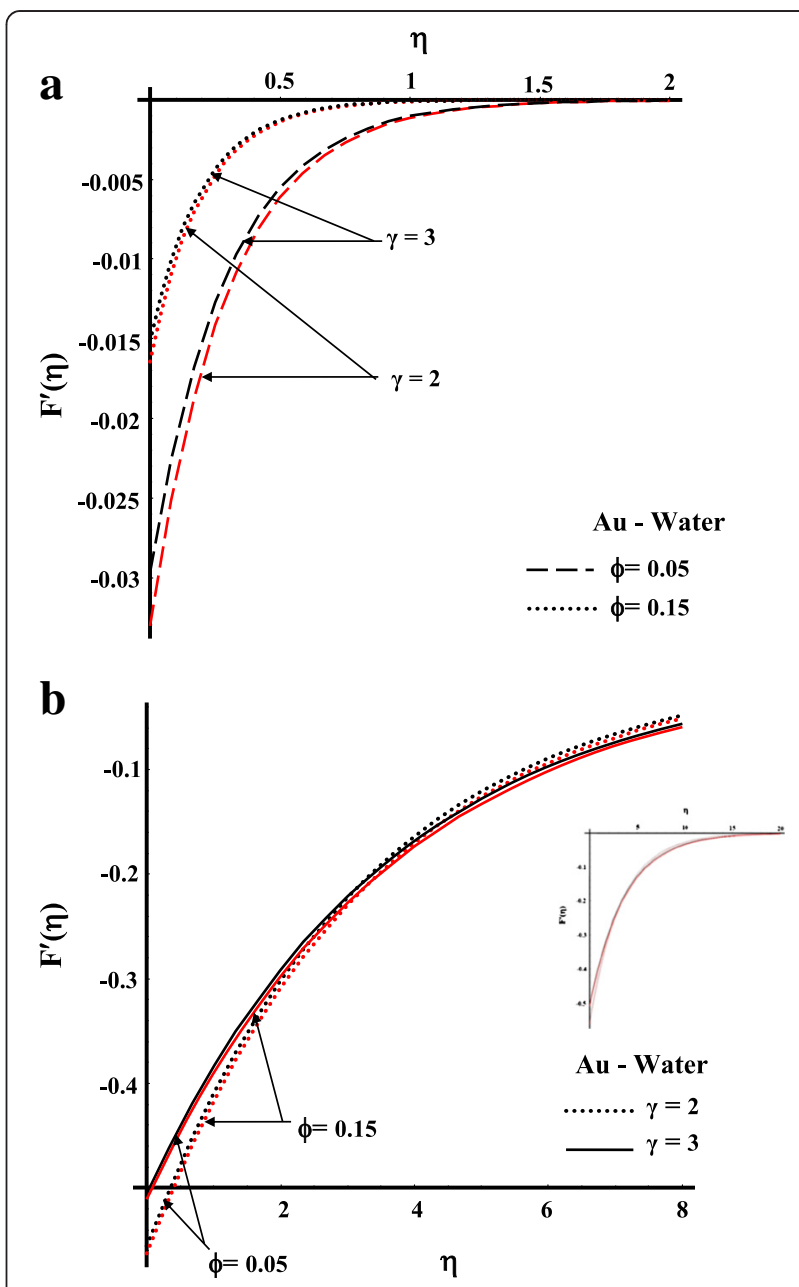

Fig. 4 a Effects of first-order slip parameter and nanoparticle volume fraction parameter on $F^{\prime}(\eta)$ with $s=2, d=-1$ and $\delta=-2$ for shrinking sheet (upper branch solution). $\mathbf{b}$ Effects of first-order slip parameter and nanoparticle volume fraction parameter on $F^{\prime}(\eta)$ with $s=2, d=$ -1 and $\delta=-2$ for shrinking sheet (lower branch solution) 


$$
\bar{u}=c \bar{x} \frac{d e^{-\beta \sqrt{\frac{c}{v_{f}}}} \bar{y}}{\left(1+\beta \gamma-\delta \beta^{2}\right)}, \quad \bar{v}=-\sqrt{c v_{f}}\left(s+\frac{d\left(1-e^{-\beta \sqrt{\frac{c}{v_{f}}}}\right)}{\beta\left(\left(1+\beta \gamma-\delta \beta^{2}\right)\right)}\right) .
$$

The shear stress at the stretching sheet characterized by the skin-friction coefficient $C_{f}$, is given by

$$
\begin{aligned}
\operatorname{Re}_{x}^{1 / 2} C_{f} & =\frac{-2}{(1-\phi)^{2.5}} F^{\prime \prime}(0) \\
& =\frac{2}{(1-\phi)^{2.5}} \frac{d \beta}{\left(1+\beta \gamma-\delta \beta^{2}\right)},
\end{aligned}
$$

where $\operatorname{Re}_{x}=\bar{x} \bar{u}_{w}(\bar{x}) / v_{f}$ is the local Reynolds number based on the stretching/shrinking velocity $\bar{u}_{w}(\bar{x})$ and $\mathrm{R}$ $\mathrm{e}_{x}^{1 / 2} C_{f}$ is the local skin-friction coefficient.

\section{Solution for the thermal transport}

Substituting the similarity transformations (11) into Eq. 9, we get

$$
\theta^{\prime \prime}+\frac{k_{f} \operatorname{Pr}\left((1-\phi)+\phi \frac{\left(\rho C_{p}\right)_{s}}{\left(\rho C_{p}\right)_{f}}\right)}{k_{n f}} F \theta^{\prime}=0,
$$

and the corresponding boundary conditions are

$$
\theta(0)=1 \text { and } \theta(\infty)=0 \text {. }
$$

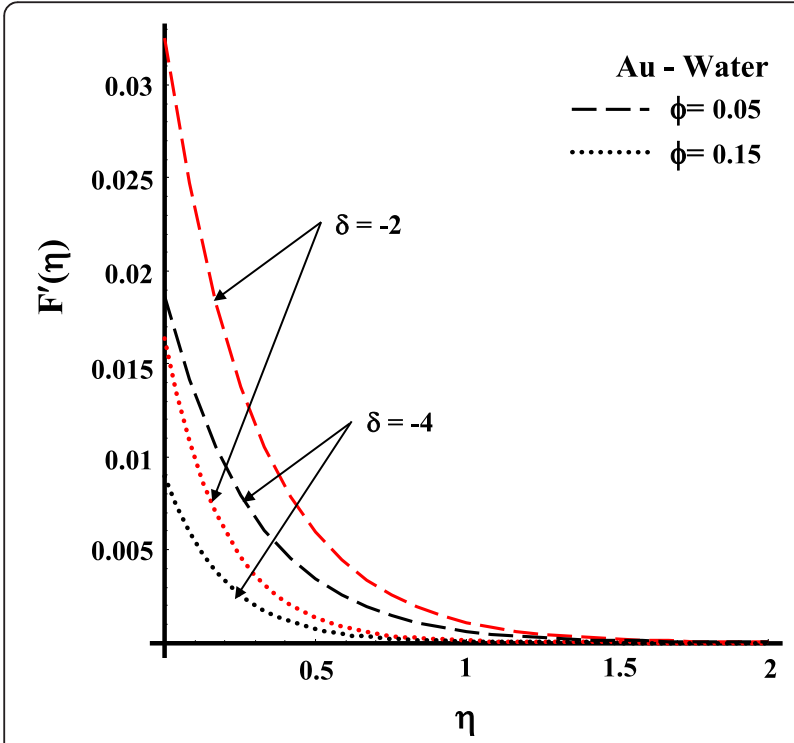

Fig. 5 Effects of second-order slip parameter and nanoparticle volume fraction parameter on $F^{\prime}(\eta)$ with $s=2, d=1$ and $\gamma=2$ for stretching sheet
The primes in Eq. 21 denote differentiation with respect to $\eta$. Making the substitution $\xi=e^{-\beta \eta}$, Eq. 21 becomes

$$
\xi \theta_{\xi \xi}+\left(I-p_{1} \xi\right) \theta_{\xi}=0
$$

where the boundary conditions (22) are given by

$$
\theta(1)=1 \text { and } \theta(0)=0 .
$$

The solution of Eq. 23 with the corresponding boundary conditions (24) in terms of $\eta$ is given by

$$
\theta(\eta)=e^{-\beta \eta(1-l)}\left(\frac{M\left(1-l, 2-l, p_{1} e^{-\beta \eta}\right)}{M\left(1-l, 2-l, p_{1}\right)}\right),
$$

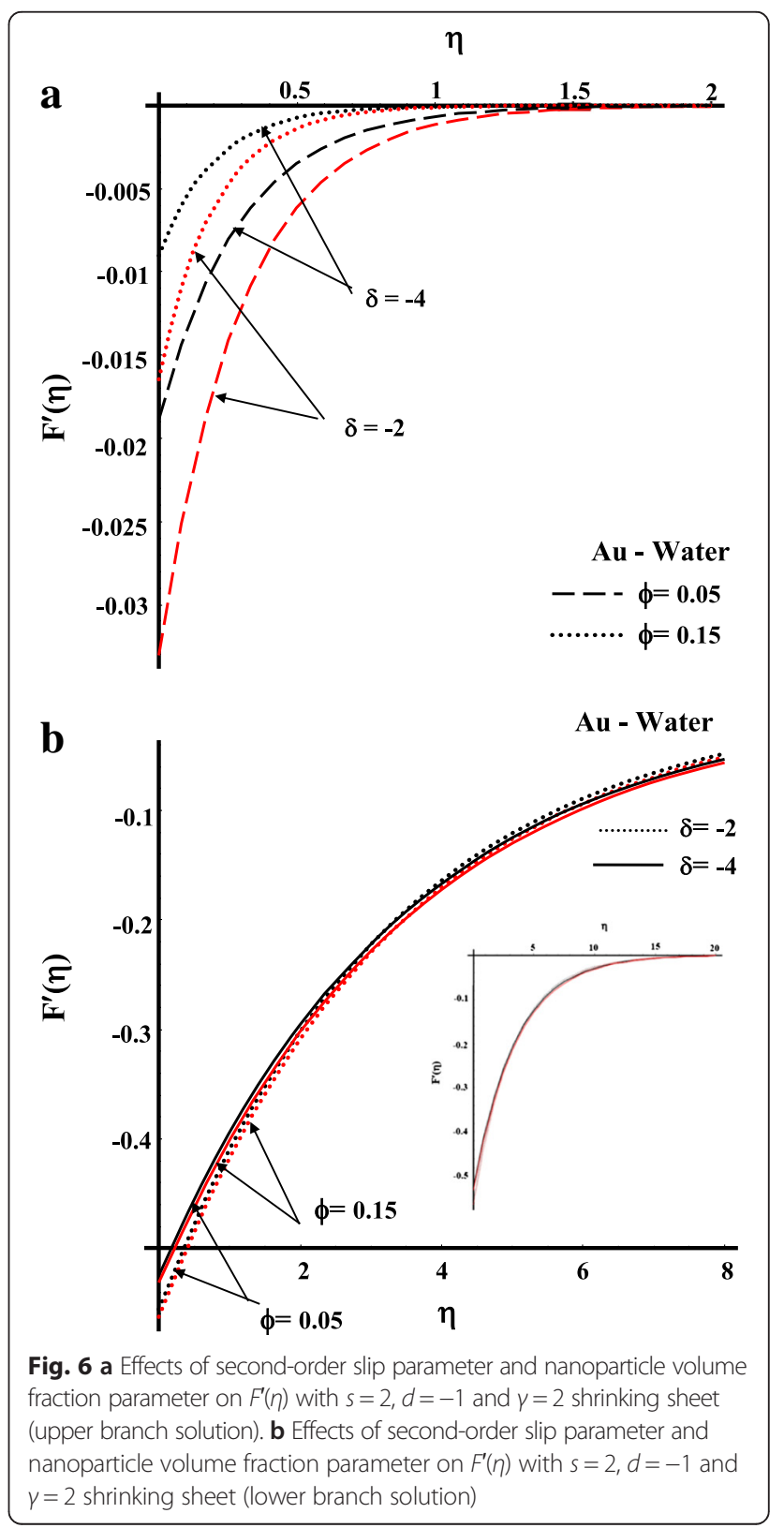




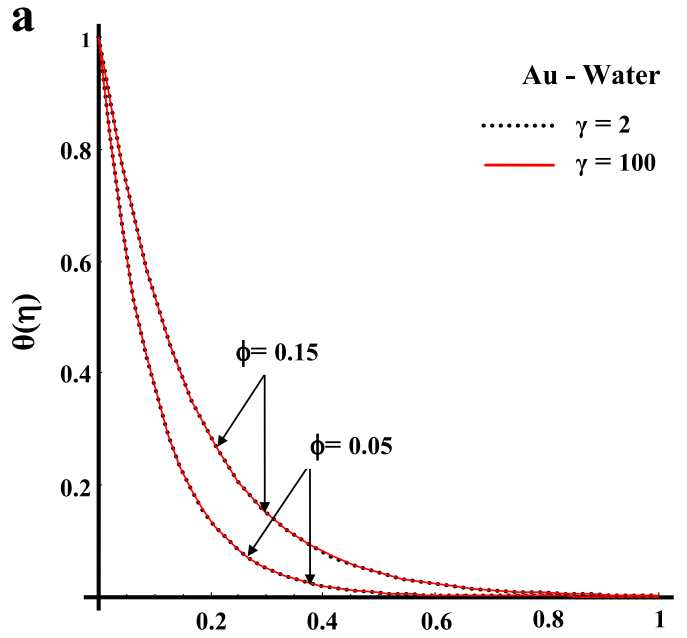

b
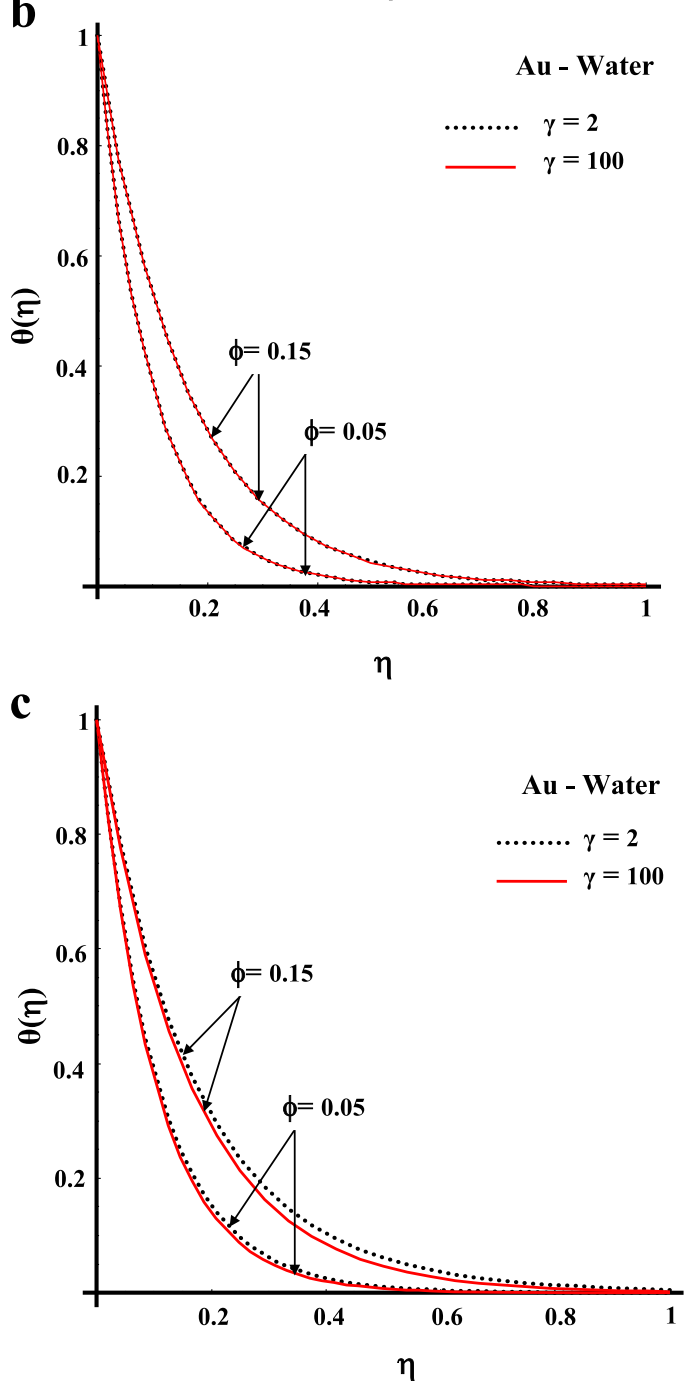

Fig. 7 a Effects of first-order slip parameter and nanoparticle volume fraction parameter on $\theta(\eta)$ with $s=2, \delta=-2, d=1$ and $\operatorname{Pr}=6.2$ for stretching sheet. $\mathbf{b}$ Effects of first-order slip parameter and nanoparticle volume fraction parameter on $\theta(\eta)$ with $s=2, \delta=-2, d=-1$ and $\operatorname{Pr}=6.2$ for shrinking sheet (upper branch solution). $\mathbf{c}$ Effects of first-order slip parameter and nanoparticle volume fraction parameter on $\theta(\eta)$ with $s=$ $2, \delta=-2, d=-1$ and $\operatorname{Pr}=6.2$ for shrinking sheet (lower branch solution)

where $M$ is the hyper geometric function (Arfken 1985) defined by

$$
\begin{aligned}
M([a],[b], z) & =1+\frac{a}{b} z+\frac{a(a+1)}{b(b+1)} \frac{z^{2}}{2 !}+\ldots \\
& =\sum_{i=0}^{\infty} \frac{(a)_{i}}{(b)_{i}} \frac{z^{i}}{i !}
\end{aligned}
$$

and

$$
\begin{aligned}
& l=1-g / \beta, \quad p_{1}=-h / \beta, \quad g=\frac{s}{D}+\frac{d}{D \beta\left(1+\beta \gamma-\delta \beta^{2}\right)}, \\
& h=\frac{d}{D \beta\left(1+\beta \gamma-\delta \beta^{2}\right)}, \quad \text { and } \quad D=\left(\frac{\operatorname{Pr} k_{f}\left((1-\phi)+\phi \frac{\left(\rho C_{p}\right)_{s}}{\left(\rho C_{p}\right)_{f}}\right)}{k_{n f}}\right)^{-1} .
\end{aligned}
$$

The quantity of practical interest in this section is the Nusselt number, $N u_{x}$, defined as

$$
N u_{x}=\frac{\bar{x} \bar{q}_{w}}{k_{f}\left(T_{w}-T_{\infty}\right)},
$$

where $\bar{q}_{w}=-\left(k_{n f}\right)\left(\frac{\partial T}{\partial \bar{y}}\right)_{\bar{y}=0}$ is the local surface heat flux. Using Eq. 6 and Eq. $11, \bar{y}=0$ we obtain the following reduced Nusselt number

$$
\operatorname{Re}_{x}^{-1 / 2} N u_{x}=\frac{k_{n f}}{k_{f}}\left[-\theta^{\prime}(0)\right]
$$

\section{Numerical method for solution}

The non-linear differential Eqs. 12 and 21 along with the boundary conditions (13) and (22) form a two-point boundary value problem and are solved using a shooting technique together with a fourth-order Runge-Kutta integration scheme by converting the non-linear differential equations into an initial value problem. In this method, we have to choose a suitable finite value of $\eta \rightarrow \infty$, say $\eta_{\infty}$. We then have to solve the system of firstorder ordinary differential equations given by 

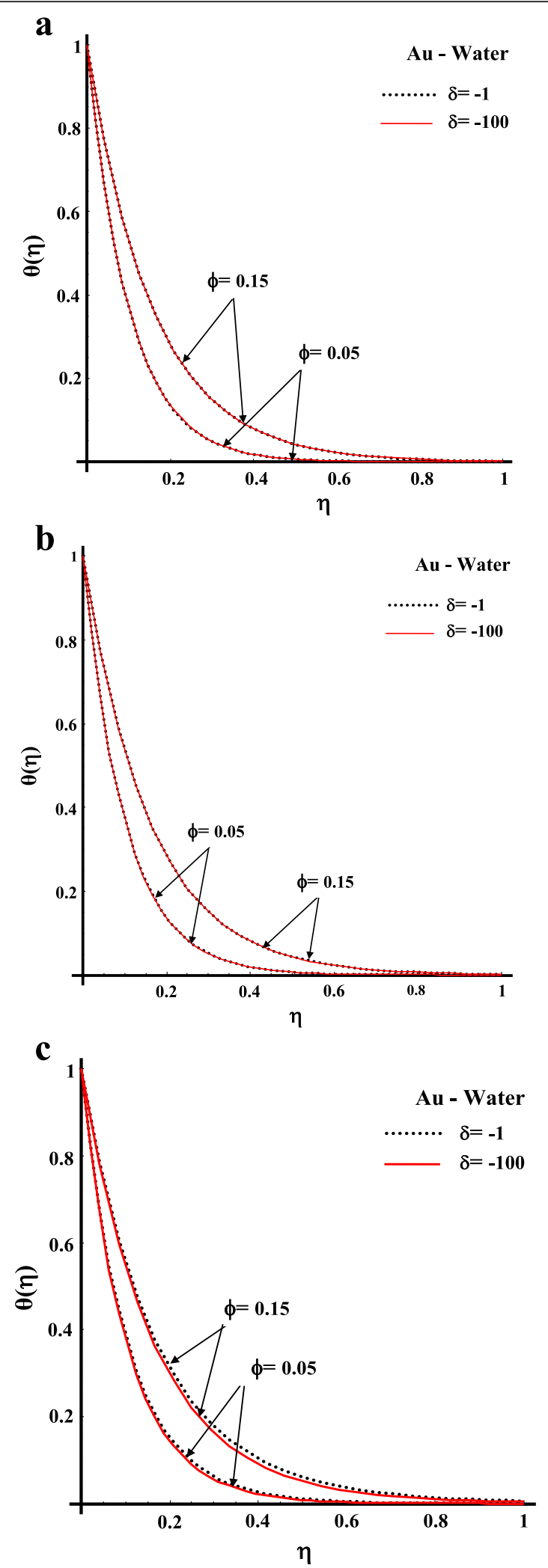

Fig. 8 a Effects of second-order slip parameter and nanoparticle volume fraction parameter on $\theta(\eta)$ with $s=2, y=2, d=1$ and $\operatorname{Pr}=6.2$ for stretching sheet. $\mathbf{b}$ Effects of second-order slip parameter and nanoparticle volume fraction parameter on $\theta(\eta)$ with $s=2, \gamma=2$, $d=-1$ and $\operatorname{Pr}=6.2$ for shrinking sheet (upper branch solution). c Effects of second-order slip parameter and nanoparticle volume fraction parameter on $\theta(\eta)$ with $s=2, \gamma=2, d=-1$ and $\operatorname{Pr}=6.2$ for shrinking sheet (lower branch solution)

$$
\begin{aligned}
& F^{\prime}=p, \quad p^{\prime}=q, \quad q^{\prime}=-(1-\phi)^{2.5}\left[1-\phi+\phi \frac{\rho_{s}}{\rho_{f}}\right]\left(F q-p^{2}\right), \quad \theta^{\prime}=z, \\
& z^{\prime}=-\frac{k_{f} \operatorname{Pr}\left((1-\phi)+\phi \frac{\left(\rho C_{p}\right)_{s}}{\left(\rho C_{p}\right)_{f}}\right)}{k_{n f}} F z,
\end{aligned}
$$

with the initial conditions

$$
F(0)=s, \quad p(0)=1+\gamma q(0)+\delta q^{\prime}(0), \quad \text { and } \quad \theta(0)=1 .
$$

To solve (29) with (30), we need the values for $q(0)$, i.e., $F^{\prime}(0)$ and $z(0)$, i.e., $\theta^{\prime}(0)$, but no such values are given. Initial guess values for $F^{\prime \prime}(0)$ and $\theta^{\prime}(0)$ are chosen, and the fourth-order Runge-Kutta integration scheme is applied to obtain a solution. Then, we compare the calculated values of $F^{\prime}(\eta)$ and $\theta(\eta)$ at $\eta_{\infty}$ with the given boundary conditions $F^{\prime}\left(\eta_{\infty}\right)=0$ and $\theta\left(\eta_{\infty}\right)=0$ and adjust the values of $F^{\prime}(0)$ and $\theta^{\prime}(0)$ using the shooting technique to give better approximation for the solution. The process is repeated until we get the results correct up to the desired accuracy of $10^{-8}$ level, which fulfils the convergence criterion.

\section{Results and discussion}

In order to get the clear insight of the physical problem, results are discussed with the help of graphical illustrations. The effects of first-order slip parameter $(\gamma)$ and second-order slip parameter $(\delta)$ with nanoparticle volume fraction parameter $(\phi)$ and Prandtl number $(\mathrm{Pr})$ on velocity and temperature profiles are discussed for Auwater in both stretching and shrinking sheet cases. The range of nanoparticle volume fraction is taken as 0 to 0.2. The Prandtl number $\operatorname{Pr}$ of the base fluid (water) is kept constant at 6.2. The values of local skin-friction coefficient $-F^{\prime \prime}(0)$ and reduced Nusselt number are tabulated for different nanofluids with nanoparticles $\mathrm{Au}, \mathrm{Ag}$, $\mathrm{Cu}, \mathrm{Al}, \mathrm{Al}_{2} \mathrm{O}_{3}$ and $\mathrm{TiO}_{2}$. In order to verify present analytical and numerical results, we have compared shrinking sheet solutions $\beta$ and $-F^{\prime \prime}(0)$ values with those of (Turkyilmazoglu 2013) and $-\theta^{\prime}(0)$ with (Wang 1989) in the absence of nanoparticle volume fraction parameter. The comparisons in the above cases are found to be in excellent agreement as shown in Tables 2, 3 and 4 . 
Table 5 Values of $-F^{\prime \prime}(0)$ for stretching sheet with $s=2$ and $d=1$

\begin{tabular}{|c|c|c|c|c|c|c|c|c|}
\hline \multirow[t]{2}{*}{$\varphi$} & \multirow[t]{2}{*}{$\gamma$} & \multirow[t]{2}{*}{$\delta$} & \multicolumn{6}{|l|}{$-F^{\prime \prime}(0)$} \\
\hline & & & $\mathrm{Au}$ & $\mathrm{Ag}$ & $\mathrm{Cu}$ & $\mathrm{Al}$ & $\mathrm{Al}_{2} \mathrm{O}_{3}$ & $\mathrm{TiO}_{2}$ \\
\hline \multirow[t]{3}{*}{0.1} & 1 & -1 & 0.17836003 & 0.22894449 & 0.24043332 & 0.29334067 & 0.28197415 & 0.27946592 \\
\hline & & -2 & 0.10032419 & 0.13553137 & 0.14429167 & 0.19075693 & 0.17962771 & 0.17728033 \\
\hline & & -3 & 0.06979895 & 0.09630406 & 0.10314181 & 0.14164856 & 0.13201804 & 0.13002428 \\
\hline \multirow[t]{3}{*}{0.1} & 1 & -1 & 0.17836003 & 0.22894449 & 0.24043332 & 0.29334067 & 0.28197415 & 0.27946592 \\
\hline & 2 & & 0.15142892 & 0.18650305 & 0.19409098 & 0.22739268 & 0.22046164 & 0.21891554 \\
\hline & 3 & & 0.13155076 & 0.15729048 & 0.16266828 & 0.18551729 & 0.18086248 & 0.17981676 \\
\hline 0.1 & 1 & -1 & 0.17836003 & 0.22894449 & 0.24043332 & 0.29334067 & 0.28197415 & 0.27946592 \\
\hline 0.15 & & & 0.16088220 & 0.21854801 & 0.23260540 & 0.30064199 & 0.28588966 & 0.28261147 \\
\hline 0.2 & & & 0.15270378 & 0.21475349 & 0.23052643 & 0.30844256 & 0.29177766 & 0.28800837 \\
\hline
\end{tabular}

\section{Results for the solution $\beta$}

Figure $2 \mathrm{a}, \mathrm{b}$ is plotted to discuss the nature of the solution $\beta$ of the algebraic Eq. 15 in both stretching and shrinking sheet cases. It is observed that there is only one physically meaningful solution in the case of a stretching sheet $(d=1)$ with suction $(s>0)$, and this is not true for a stretching sheet with injection $(s<0)$, or for a shrinking sheet $(d=-1)$ as discussed in (Gorder and Vajravelu 2011) which is valid for the present case also. Closely look at Fig. 2a, it is seen that the solution $\beta$ decreases with the increase of $\gamma$ and $|\delta|$ and it increases with $\phi$. When comparing the solution domain with Fang et al. (2010), it is clear from Fig. 2b that the critical values of $s_{\text {critical }}(\gamma, \delta, \phi)$ are located in the range $0<s<2$ depending on the specific value of $\gamma, \delta$ and $\phi$. When the suction parameter is less than $s_{\text {critical }}(\gamma, \delta, \phi)$, there is no physically valid solution for the problem. For the upper branch solution, the value of $\beta$ increases with $\gamma,|\delta|$ and $\phi$, and an opposite behaviour is noted for lower branch solution. It is very interesting to note that Fang et.al (2010) obtained the $s_{\text {critical }}$ point near $s \geq 1$ with $\gamma=3$ and $\delta=-3$ in the absence of $\phi$ (for ordinary fluid) but for nanofluids $s_{\text {critical }}$ lies between 0 and 1 with $\gamma=3$ and $\delta=-3$. It may be concluded that the presence of nanoparticles decreases the value of $s_{\text {critical }}$. Eq. 17IV gives a unique solution for the stretching sheet and upper branch solution for the shrinking sheet. The lower branch solution is obtained by either Eq. 17II or Eq. 17III which depends on the choice of physical parameters.

\section{Results for velocity profile}

The effects of the first-order slip parameter $(\gamma)$ and nanoparticle volume fraction $(\phi)$ on the velocity profile $F^{\prime}(\eta)$ of Au-water in the case of stretching sheet are shown in Fig. 3 with $s=2, d=1$ and $\delta=-2$. It is clear from the figure that the velocity component reduces with an increase in $\gamma$. The presence of nanoparticles in base fluid decreases the velocity component $F^{\prime}(\eta)$. The combined effect of $\gamma$ and $\phi$ leads to the decrease of the momentum boundary-layer thickness. When slip occurs, the flow velocity near the sheet is no longer equal to the stretching velocity of the sheet. With the increase in $\gamma$, such slip velocity increases and consequently fluid velocity decreases because under the slip condition, the pulling of the stretching sheet can be only partly

Table 6 Values of $-F^{\prime \prime}(0)$ for shrinking sheet with $s=2$ and $d=-1$

\begin{tabular}{|c|c|c|c|c|c|c|c|c|}
\hline \multirow[t]{2}{*}{$\varphi$} & \multirow[t]{2}{*}{$\gamma$} & \multirow[t]{2}{*}{$\delta$} & \multicolumn{6}{|l|}{$-F^{\prime \prime}(0)$} \\
\hline & & & $\mathrm{Au}$ & $\mathrm{Ag}$ & $\mathrm{Cu}$ & $\mathrm{Al}$ & $\mathrm{Al}_{2} \mathrm{O}_{3}$ & $\mathrm{TiO}_{2}$ \\
\hline \multirow[t]{3}{*}{0.1} & 1 & $-1^{U}$ & -0.17960669 & -0.23258925 & -0.24494149 & -0.30368830 & -0.2908699 & -0.28804534 \\
\hline & & $-2^{U}$ & -0.10077851 & -0.13712679 & -0.14637168 & -0.19768896 & -0.18496089 & -0.18231704 \\
\hline & & $-3^{U}$ & -0.07003008 & -0.09717569 & -0.10430211 & -0.14611977 & -0.13531669 & -0.13311438 \\
\hline \multirow[t]{3}{*}{0.1} & 1 & $-1^{U}$ & -0.17960669 & -0.23258925 & -0.24494149 & -0.30368830 & -0.2908699 & -0.28804534 \\
\hline & 2 & & -0.15218956 & -0.18845647 & -0.19643731 & -0.23208310 & -0.22461869 & -0.22295147 \\
\hline & 3 & & -0.13204851 & -0.15845659 & -0.16404150 & -0.15100590 & -0.15002771 & -0.14984098 \\
\hline 0.1 & 1 & $-1^{U}$ & -0.17960669 & -0.23258925 & -0.24494149 & -0.30368830 & -0.2908699 & -0.28804534 \\
\hline 0.15 & & & -0.16168775 & -0.22152807 & -0.23650994 & -0.31185534 & -0.29528583 & -0.29158832 \\
\hline 0.2 & & & -0.15335046 & -0.21751626 & -0.23428173 & -0.32032628 & -0.30192805 & -0.29767731 \\
\hline
\end{tabular}

Uenotes upper branch solutions 
Table 7 Values of $-F^{\prime \prime}(0)$ for shrinking sheet with $s=2$ and $d=-1$

\begin{tabular}{lllllllll}
\hline$\varphi$ & $Y$ & $\delta$ & $-F^{\prime \prime}(0)$ & & & \\
\cline { 3 - 7 } & & & $\mathrm{Au}$ & $\mathrm{Ag}$ & $\mathrm{Cu}$ & $\mathrm{Al}$ & $\mathrm{Al}_{2} \mathrm{O}_{3}$ & $\mathrm{TiO}_{2}$ \\
\hline 0.1 & 1 & $-1^{\mathrm{L}}$ & -0.24339911 & -0.2479996 & -0.24938371 & -0.25987209 & -0.25666292 & -0.25606086 \\
& & $-2^{\mathrm{L}}$ & -0.21750716 & -0.22045728 & -0.22132829 & -0.22765880 & -0.22577468 & -0.22541583 \\
& & $3^{\mathrm{L}}$ & -0.19862221 & -0.20066582 & -0.20126139 & -0.20547326 & -0.20424223 & -0.20400553 \\
0.1 & 1 & $-1^{\mathrm{L}}$ & -0.24339911 & -0.2479996 & -0.24938371 & -0.25987209 & -0.25666292 & -0.25606086 \\
& 2 & & -0.18144291 & -0.18391484 & -0.18464900 & -0.19005022 & -0.18843012 & -0.18812281 \\
& 3 & & -0.14570031 & -0.14724986 & -0.14770633 & -0.18803118 & -0.18313229 & -0.18202955 \\
0.1 & 1 & $-1^{L}$ & -0.24339911 & -0.2479996 & -0.24938371 & -0.25987209 & -0.25666292 & -0.25606086 \\
0.15 & & & -0.24217275 & -0.24688249 & -0.24842191 & -0.26252200 & -0.25767099 & -0.25682109 \\
0.2 & & & -0.24164250 & -0.24650170 & -0.24818008 & -0.26620015 & -0.25937464 & -0.25825563 \\
\hline
\end{tabular}

${ }^{\mathrm{L}}$ Denotes lower branch solutions

transmitted to the fluid. The presence of nanoparticles and the first-order slip lead to decrease the momentum boundary-layer thickness.

Figure 4a, b depicts the effects of $\gamma$ and $\phi$ on the velocity profile in the case of shrinking sheet. Velocity profiles for upper and lower branch solutions are shown in Fig. 4a, b, respectively. It is noted that an increase in $\gamma$ and $\phi$ leads to increase the nanofluid velocity profile in upper branch solution case. The velocity component $F$ ' $(\eta)$ increases as $\gamma$ increases for some values of $\eta$ in lower branch solution case. As $\eta$ rises, the increasing values of $\gamma$ lead to decrease the velocity of Au-water. Increasing values of both the parameters $\gamma$ and $\phi$ increase the velocity of Au-water in the case of upper branch solution. It is seen that the first-order slip and the nanoparticle volume fraction parameters have an opposite effect on the velocity profile of Au-water in the case of shrinking sheet upper branch solution compared to stretching sheet.
The effects of second-order slip parameter $\delta$ and nanoparticle volume fraction on $F^{\prime}(\eta)$ are shown in Fig. 5 in the case of stretching sheet. It is clear that the velocity profile decreases with an increase in $|\delta|$ and $\phi$. The combined effect of both $|\delta|$ and $\phi$ affects the nanofluid velocity profile.

Figure 6a, b is plotted for $F^{\prime}(\eta)$ for different values of $\delta$ and $\phi$ in the case of shrinking sheet. The velocity profile for upper branch solution and lower branch solution is presented in Fig. 6a, b, respectively. It is observed that the increasing values of both $|\delta|$ and $\phi$ lead to increase the velocity of the nanofluid in case of upper branch solution. The second-order slip parameter $(|\delta|)$ has the same effect as first-order slip parameter $\gamma$ on nanofluid velocity in the case of lower branch solution.

\section{Results for temperature profile}

Figure $7 \mathrm{a}-\mathrm{c}$ illustrates the effects of $\gamma$ and $\phi$ on temperature profile of $\mathrm{Au}$-water in case of stretching

Table 8 Values of $-\theta^{\prime}(0)$ for stretching sheet with $s=2$ and $d=1$

\begin{tabular}{|c|c|c|c|c|c|c|c|c|c|}
\hline \multirow[t]{2}{*}{$\varphi$} & \multirow[t]{2}{*}{$P r$} & \multirow[t]{2}{*}{$\gamma$} & \multirow[t]{2}{*}{$\delta$} & \multicolumn{6}{|l|}{$-\theta^{\prime}(0)$} \\
\hline & & & & $\overline{\mathrm{Au}}$ & $\mathrm{Ag}$ & $\mathrm{Cu}$ & $\mathrm{Al}$ & $\mathrm{Al}_{2} \mathrm{O}_{3}$ & $\mathrm{TiO}_{2}$ \\
\hline \multirow[t]{3}{*}{$\overline{0.1}$} & 6.2 & 1 & -1 & 8.96763224 & 8.95931998 & 9.18190038 & 9.00877818 & 9.21615941 & 9.54160066 \\
\hline & & & -2 & 8.96168204 & 8.94802231 & 9.16900511 & 8.98720064 & 9.19663750 & 9.52240216 \\
\hline & & & -3 & 8.95934365 & 8.94322633 & 9.16341448 & 8.97658448 & 9.18734256 & 9.51332346 \\
\hline \multirow[t]{3}{*}{0.1} & 6.2 & 1 & -1 & 8.96763224 & 8.95931998 & 9.18190038 & 9.00877818 & 9.21615941 & 9.54160066 \\
\hline & & 2 & & 8.96558323 & 8.95420816 & 9.17571320 & 8.99499657 & 9.20449933 & 9.53029404 \\
\hline & & 3 & & 8.96406781 & 8.95066926 & 9.17148775 & 8.98607716 & 9.19687670 & 9.52288576 \\
\hline \multirow[t]{3}{*}{0.1} & 6.2 & 1 & -1 & 8.96763224 & 8.95931998 & 9.18190038 & 9.00877818 & 9.21615941 & 9.54160066 \\
\hline & 7 & & & 10.1235168 & 10.1125894 & 10.3633504 & 10.1642802 & 10.39941256 & 10.76698017 \\
\hline & 8 & & & 11.5682639 & 11.5539900 & 11.8399581 & 11.6083404 & 11.878192 & 12.2984277 \\
\hline 0.1 & 6.2 & 1 & -1 & 8.96763224 & 8.95931998 & 9.18190038 & 9.00877818 & 9.21615941 & 9.54160066 \\
\hline 0.15 & & & & 7.66402787 & 7.64828309 & 7.93848451 & 7.71063957 & 7.97732598 & 8.39192699 \\
\hline 0.2 & & & & 6.56452718 & 6.54371636 & 6.88156091 & 6.61657544 & 6.92309899 & 7.39738516 \\
\hline
\end{tabular}


Table 9 Values of $-\theta^{\prime}(0)$ for shrinking sheet with $s=2$ and $d=-1$

\begin{tabular}{|c|c|c|c|c|c|c|c|c|c|}
\hline \multirow[t]{2}{*}{$\bar{\varphi}$} & \multirow[t]{2}{*}{$\operatorname{Pr}$} & \multirow[t]{2}{*}{$\gamma$} & \multirow[t]{2}{*}{$\delta$} & \multicolumn{6}{|l|}{$-\theta^{\prime}(0)$} \\
\hline & & & & $\overline{\mathrm{Au}}$ & $\mathrm{Ag}$ & $\mathrm{Cu}$ & $\mathrm{Al}$ & $\mathrm{Al}_{2} \mathrm{O}_{3}$ & $\mathrm{TiO}_{2}$ \\
\hline \multirow[t]{3}{*}{$\overline{0.1}$} & 6.2 & 1 & $-1^{0}$ & 8.94000235 & 8.90171270 & 9.11423777 & 8.86916843 & 9.09739368 & 9.42623649 \\
\hline & & & $-2^{U}$ & 8.94616160 & 8.91401373 & 9.12852713 & 8.89693791 & 9.12136061 & 9.44957677 \\
\hline & & & $-3^{u}$ & 8.94855242 & 8.91909851 & 9.13453448 & 8.90987130 & 9.13222539 & 9.46010186 \\
\hline \multirow[t]{3}{*}{0.1} & 6.2 & 1 & $-1^{U}$ & 8.94000235 & 8.90171270 & 9.11423777 & 8.86916843 & 9.09739368 & 9.42623649 \\
\hline & & 2 & & 8.94214951 & 8.90742644 & 9.12130754 & 8.88811143 & 9.11251719 & 9.44072796 \\
\hline & & 3 & & 8.94372350 & 8.91128391 & 9.12598796 & 8.68802101 & 8.90192631 & 9.22856981 \\
\hline \multirow[t]{3}{*}{0.1} & 6.2 & 1 & $-1^{U}$ & 8.94000235 & 8.90171270 & 9.11423777 & 8.86916843 & 9.09739368 & 9.42623649 \\
\hline & 7 & & & 10.0948131 & 10.0532790 & 10.2938502 & 10.0219901 & 10.2781938 & 10.6492582 \\
\hline & 8 & & & 11.5384374 & 11.4929308 & 11.76858011 & 11.4633546 & 11.7544989 & 12.1783283 \\
\hline 0.1 & 6.2 & 1 & $-1^{U}$ & 8.94000235 & 8.90171270 & 9.11423777 & 8.86916843 & 9.09739368 & 9.42623649 \\
\hline 0.15 & & & & 7.64451675 & 7.60052168 & 7.87980673 & 7.55820025 & 7.85502622 & 8.27413557 \\
\hline 0.2 & & & & 6.54876634 & 6.50066644 & 6.82683043 & 6.44687288 & 6.79331037 & 7.27309052 \\
\hline
\end{tabular}

sheet, shrinking sheet upper and lower branch solutions, respectively. It is clear that from Fig. 7a, the temperature profile increases as $\phi$ and $\gamma$ increase. The combined effect of these parameters increases the thermal boundarylayer thickness. The temperature increases as $\phi$ increases and decreases as $\gamma$ increases in the case of shrinking sheet (upper and lower branch solutions [Fig. 7b, c]). It can be seen that the presence of first-order slip $(\gamma)$ considerably decreases the temperature profile in case of shrinking sheet lower branch solution compared to upper branch solution.

The effects of $\delta$ and $\phi$ on temperature profile of $\mathrm{Au}$-water in case of stretching sheet, shrinking sheet upper and lower branch solutions are elucidated in Fig. 8a-c. It is noted that the temperature profile increases with the increasing values of $\phi$ and $|\delta|$ for stretching sheet (Fig. 8a). The temperature profile decreases with the increasing values of $|\delta|$ and increases with the increase of $\phi$ in both upper and lower branch solutions (Fig. $8 \mathrm{~b}, \mathrm{c}$ ). It is observed that the second-order slip parameter $(|\delta|)$ increases the thermal boundary-layer thickness in the case of stretching sheet and decreases the thickness of the thermal boundary-layer in the case of shrinking sheet upper and lower branch solutions.

\section{Results for local skin-friction coefficient and reduced Nusselt number}

The values of $-F^{\prime \prime}(0)$ for different nanofluids are presented in Tables 5, 6 and 7 for stretching sheet, shrinking sheet upper and lower branch solutions, respectively.

Table 10 Values of $-\theta^{\prime}(0)$ for shrinking sheet with $s=2$ and $d=-1$

\begin{tabular}{|c|c|c|c|c|c|c|c|c|c|}
\hline \multirow[t]{2}{*}{$\varphi$} & \multirow[t]{2}{*}{$\operatorname{Pr}$} & \multirow[t]{2}{*}{$\gamma$} & \multirow[t]{2}{*}{$\delta$} & \multicolumn{6}{|l|}{$-\theta^{\prime}(0)$} \\
\hline & & & & $\mathrm{Au}$ & $\mathrm{Ag}$ & $\mathrm{Cu}$ & $\mathrm{Al}$ & $\mathrm{Al}_{2} \mathrm{O}_{3}$ & $\mathrm{TiO}_{2}$ \\
\hline \multirow[t]{3}{*}{0.1} & 6.2 & 1 & $-1^{L}$ & 8.60736217 & 8.59049482 & 8.81044994 & 8.61956121 & 8.83149871 & 9.15788685 \\
\hline & & & $-2^{L}$ & 8.62608298 & 8.60907041 & 8.82893122 & 8.63719619 & 8.84946087 & 9.17587696 \\
\hline & & & $-3^{L}$ & 8.64048070 & 8.62324859 & 8.84300832 & 8.65047682 & 8.86301863 & 9.18946312 \\
\hline \multirow[t]{3}{*}{0.1} & 6.2 & 1 & $-1^{\mathrm{L}}$ & 8.60736217 & 8.59049482 & 8.81044994 & 8.61956121 & 8.83149871 & 9.15788685 \\
\hline & & 2 & & 8.65420733 & 8.63587484 & 8.85528708 & 8.66033358 & 8.87359737 & 9.20016328 \\
\hline & & 3 & & 8.68509934 & 8.66593785 & 8.88504809 & 8.89938679 & 9.121764781 & 9.44963886 \\
\hline \multirow[t]{3}{*}{0.1} & 6.2 & 1 & $-1^{\mathrm{L}}$ & 8.60736217 & 8.59049482 & 8.81044994 & 8.61956121 & 8.83149871 & 9.15788685 \\
\hline & 7 & & & 9.76431791 & 9.74436674 & 9.99234718 & 9.77475466 & 10.01464203 & 10.38317866 \\
\hline & 8 & & & 11.2100172 & 11.1862653 & 11.46930691 & 11.21844264 & 11.49324104 & 11.91447074 \\
\hline 0.1 & 6.2 & 1 & $-1^{\mathrm{L}}$ & 8.60736217 & 8.59049482 & 8.81044994 & 8.61956121 & 8.83149871 & 9.15788685 \\
\hline 0.15 & & & & 7.30365859 & 7.28042086 & 7.56808496 & 7.31887513 & 7.59124819 & 8.00706347 \\
\hline 0.2 & & & & 6.20217481 & 6.17480694 & 6.51041063 & 6.22263870 & 6.53492338 & 7.01054907 \\
\hline
\end{tabular}

LDenotes lower branch solutions 
On observation of these tables, it reveals that local skinfriction coefficient $-F^{\prime \prime}(0)$ decreases with the increasing values of $\gamma$ and $|\delta|$ in stretching sheet case and it increases with the above said parameters in shrinking sheet case (both upper and lower branch). The increasing values of $\phi$ decrease the local skin-friction coefficient of $\mathrm{Au}, \mathrm{Ag}$ and $\mathrm{Cu}$ nanofluids and increase the $-F^{\prime \prime}(0)$ values of $\mathrm{Al}, \mathrm{Al}_{2} \mathrm{O}_{3}$ and $\mathrm{TiO}_{2}$ nanofluids in stretching sheet, and an opposite effect has been seen in shrinking sheet case. The values of skin-friction coefficient are higher for $\mathrm{Al}$-water and lower for $\mathrm{Au}$-water in stretching sheet and in the case of shrinking sheet; the values of $-F^{\prime \prime}$ (0) are higher for $\mathrm{Au}$-water and lower for Al-water compared to other nanofluids.

The values of reduced Nusselt number $-\theta^{\prime}(0)$ are tabulated in Tables 8, 9 and 10 for stretching sheet, shrinking sheet upper and lower branch solutions, respectively. It is clear from Table 8 that the reduced Nusselt number decreases with the increasing values of $\gamma,|\delta|$ and $\phi$, and it increases as $\mathrm{Pr}$ increases in stretching sheet. In the case of shrinking sheet (both upper and lower branch), the reduced Nusselt number increases with $\gamma,|\delta|$ and $P r$, and it decreases with $\phi$. The reduced Nusselt number values are higher for $\mathrm{TiO}_{2}$-water and lower for $\mathrm{Ag}$-water in the stretching sheet and shrinking sheet lower branch solution cases. $\mathrm{TiO}_{2}$-water has higher Nusselt number and $\mathrm{Al}$-water has lower Nusselt number in the case of shrinking sheet upper branch solution.

\section{Conclusions}

An analysis has been carried out to study the heat transfer characteristics of a water-based nanofluid over a stretching/shrinking sheet with second-order slip flow model. The basic boundary-layer non-linear partial differential equations have been converted into a set of non-linear ordinary differential equations by using scaling transformations. An exact solution to the momentum equation is obtained and the solution of energy equation is obtained in terms of a hypergeometric function for different water-based nanofluids containing $\mathrm{Au}$, $\mathrm{Ag}, \mathrm{Cu}, \mathrm{Al}, \mathrm{Al}_{2} \mathrm{O}_{3}$ and $\mathrm{TiO}_{2}$ nanoparticles, and the analytical solutions are verified by the solutions obtained by the fourth-order Runge-Kutta with shooting method and the following results are obtained:

- It is observed that there is only one physically meaningful solution in the case of a stretching sheet with suction, and this is not true for a stretching sheet with injection or for a shrinking sheet. Dual solutions are obtained in shrinking sheet beyond a suction critical point which are classified as upper and lower branch solutions. The presence of nanoparticles decreases the suction critical point.
- Equation 17IV gives a unique solution for the stretching sheet and upper branch solution for the shrinking sheet. The lower branch solution is obtained by either Eq. 17II or Eq. 17III which depends on the choice of physical parameters.

- The velocity profile of the nanofluid decreases with the increasing vales of first-order $(\gamma)$ and secondorder slip $(|\delta|)$ parameters in stretching and shrinking sheet lower branch solution cases (for large values of $\eta)$. The increasing values of first $(\gamma)$ and second-order slip parameters $(|\delta|)$ increases the velocity profile in cases of shrinking sheet upper and lower branch solutions (for small values of $\eta$ ). The increasing values of nanoparticle volume fraction decrease the velocity components in stretching sheet and shrinking sheet lower branch solution and increase the velocity profile in shrinking sheet lower branch solution.

- The temperature profile of the nanofluid rises with the increasing values of first-order and second-order $(|\delta|)$ slip parameters in the stretching sheet case and reduces with the above-said parameters in shrinking sheet case. The increasing values of nanoparticle volume fraction parameter increase the temperature of the nanofluid in both stretching and shrinking sheets.

Competing interests

The authors declare that they have no competing interests.

Authors' contributions

All authors read and approved the final manuscript.

\section{Acknowledgements}

EM acknowledges the financial support from the National Research Foundation, South Africa, under Grant Number 76868.

\section{Author details}

${ }^{1}$ Shanghai Key Lab of Vehicle Aerodynamics and Vehicle Thermal Management Systems, Tongji University, Address: 4800 Cao An Rd., Jiading, Shanghai 201804, China.. ${ }^{2}$ ENN-Tongji Clean Energy Institute of advanced studies, Shanghai Jiao Tong University, Shanghai, China.. ${ }^{3}$ Department of Mathematics, Sri Ramakrishna Mission Vidyalaya College of Arts and Science, Coimbatore 641 020, India. ${ }^{4}$ Department of Mathematics, Providence College for Women, Coonoor 643 104, India. ${ }^{5}$ Department of Mechanical Engineering, Babol University of Technology, Babol, Islamic Republic of Iran. ${ }^{6}$ DST/NRF Centre of Excellence in the Mathematical and Statistical Sciences, School of Computer Science and Applied Mathematics, University of the Witwatersrand, Private Bag 3, Johannesburg, Wits 2050, South Africa.

Received: 4 October 2015 Accepted: 4 February 2016

Published online: 22 February 2016

\footnotetext{
References

Abdul Hakeem, AK, Kalaivanan, R, Vishnu Ganesh, N, Ganga, B. (2014) Effect of partial slip on hydromagnetic flow over a porous strecting sheet with nonuniform heat source/sink, thermal radiation and wall mass transfer. Ain Shams Engineering Journal. http://dx.doi.org/10.1016/j.asej.2014.02.006

Akyildiz, F. T., Bellout, H., \& Vajravelu, K. (2011). Gorder RAV (2011) Existence results for third order nonlinear boundary value problems arising in nano boundary layer fluid flows over stretching surfaces. Nonlinear Analysis: Real World Applications, 12, 2919-2930.

Arfken, G. (1985). Confluent hypergeometric function, mathematical methods for physicists (3rd ed., pp. 753-758). Orlando, FL: Academic.
} 
Beskok, A., \& Karniadakis, G. E. (1994). Simulation of heat and momentum transfer in complex micro-geometries. Journal of Thermophysics and Heat Transfer, 8, 355-370.

Beskok, A., \& Karniadakis, G. E. (1999). A model for flows in channels pipes and ducts at micro and nano scales. Microscale Thermophysical Engineering, 3, 43-77.

Das, K. (2012). Slip flow and convective heat transfer of nanofluids over a permeable stretching surface. Computers and Fluids, 64, 34-42.

Das, S. K., Choi, S. U. S., Yu, W., \& Pradeep, T. (2007). Nanofluids: science technology. New Jersey: Wiley.

Domkundwar, A. V., \& Domdundwar, V. M. (2004). Heat and mass transfer data book. Delhi: Dhanpa rai and co (p) Ltd, Educational and Technical Publishers.

Fang, T. G., Zhang, J., \& Yao, S. S. (2010). Slip magneto hydrodynamic viscous flow over a permeable shrinking sheet. Chinese Physics Letters, 27(12), 124702.

Fang, T., Yao, S., Zhang, J., \& Aziz, A. (2010). Viscous flow over a shrinking sheet with second-order slip flow model. Communications in Nonlinear Science and Numerical Simulation, 15, 1831-1842.

Freidoonimehr N, Rashidi MM (2015) DualSolutions for MHD Jeffery-Hamel Nano- fluid Flow in Non-parallel Walls usingPredictor Homotopy Analysis Method. Journal of Applied Fluid Mechanics, In press.

Ganga, B, Saranya, S, Vishnu Ganesh, N, Abdul Hakeem, AK. (2014) Effects of space and temperature dependent internal heat generation/absorption on MHD flow of a nanofluid over a stretching sheet. Journal of Hydrodynamics, Ser. B. Accepted (2014)

Garoosi, F., Jahanshaloo, L., Rashidi, M. M., Badakhsh, A., \& Ali, M. A. (2015) Numerical simulation of natural convection of the nanofluid in heat exchangers using a Buongiorno model. Applied Mathematics and Computation, 254, 183-203.

Gorder, R. A. V., \& Vajravelu, K. (2011). Multiple solutions for hydromagnetic flow of a second grade fluid over a stretching ors shrinking sheet. Quarterly of Applied Mathematics, 69, 405-424.

Gorder, R. A. V., Sweet, E., \& Vajravelu, K. (2010). Nano boundary layers over stretching surfaces. Communications in Nonlinear Science and Numerical Simulation, 15, 1494-1500.

Govindaraju, M, Vishnu Ganesh, N, Ganga, B, Abdul Hakeem, AK. (2014) Entropy generation analysis of magneto hydrodynamic flow of a nanofluid over a stretching sheet. Journal of the Egyptian Mathematical Society, http://dx.doi. org/10.1016/j.joems.2014.04.005

Hamad, M. A. A. (2011). Analytical solution of natural convection flow of a nanofluid over a linearly stretching sheet in the presence of magnetic field. International communications in heat and mass transfer, 38, 487-492.

Hatami, M., Sheikholeslami, M., \& Ganji, D. D. (2014). Nanofluid flow and heat transfer in an asymmetric porous channel with expanding or contracting wall. Journal of Molecular Liquids, 195, 230-239.

Ibrahim, W., \& Shankar, B. (2013). MHD boundary layer flow and heat transfer of a nanofluid past a permeable stretching sheet with velocity, thermal and solutal slip boundary conditions. Comput Fluids, 75, 1-10.

Khan, W. A., \& Pop, I. (2010). Boundary layer flow of a nanofluid past a stretching sheet. International Journal of Heat and Mass Transfer, 53, 2477-2483.

Kuznetsov, A. V., \& Nield, D. A. (2010). Natural convective boundary-layer flow of a nanofluid past a vertical plate. International Journal of Thermal Sciences, 49, 243-247.

Maxwell JC (1879) On stresses in rarefied gases arising from inequalities of temperature. Philosophical Transactions of the royal society of London. 170:231-256

Miklavcic, M., \& Wang, C. Y. (2006). Viscous flow due to a shrinking sheet. Quart Appl Math, 64(2), 283-290.

Nandeppanavar, M. M., Vajravelu, K., Abel, M. S., \& Siddalingappa, M. N. (2012). Second-order slip flow and heat transfer over a stretching sheet with nonlinear Navier boundary condition. International Journal of Thermal Sciences, $58,143-150$.

Noghrehabad, A., \& Pourrajab, R. (2012). Effect of partial slip boundary condition on the flow and heat transfer of nanofluids past stretching sheet prescribed constant wall temperature. International Journal of Thermal Sciences, 54, 253-261.

Rashidi, M. M., \& Erfani, E. (2011). The modified differential transform method for investigating nano boundary-layers over stretching surfaces. Int I Numerical Methods for Heat and Fluid Flow, 21(7), 864-883.

Rashidi, MM, Freidoonimehr, N,Hosseini, A, Anwar Bég, O, Hung, TK. (2013) Homotopy simulation of nanofluid dynamics from a non-linearly stretching isothermal permeable sheet with transpiration, Meccanica, In press, doi:10.1007/s11012-013-9805-9.

Rashidi, M. M., Vishnu Ganesh, N., Abdul Hakeem, A. K., \& Ganga, B. (2014). Buoyancy effect on MHD flow of nanofluid over a stretching sheet in the presence of thermal radiation. Journal of Molecular Liquids, 198, 234-238.

Rashidi, MM, Momoniat, E, Mohammad, F, Basiri Parsa, A. (2014) Lie group solution for free convective flow of a nanofluid past a chemically reacting horizontal plate in porous media, mathematical problems in engineering, Article number 239082

Sahoo, B. (2010). Flow and heat transfer of a non-Newtonian fluid past a stretching sheet with partial slip. Communications in Nonlinear Science and Numerical Simulation, 15, 602-615.

Sakiadis, B. C. (1961a). Boundary-layer behaviour on continuous solid surfaces: I. Boundary-layer equations for two dimensional and axisymmetric flow. AICHE Journal, 7, 26-28.

Sakiadis, B. C. (1961b). Boundary-layer behaviour on continuous solid surfaces: II. The boundary- layer on a continuous flat surface. A/CHE Journal, 7, 221-225.

Sakiadis, B. C. (1961c). Boundary-layer behaviour on continuous solid surfaces: III. The boundary- layer on a continuous cylindrical surface. AICHE Journal, 7, 467-472

Sheikholeslami, M., \& Ganji, D. D. (2014). Numerical investigation for two phase modeling of nanofluid in a rotating system with permeable sheet. $J \mathrm{Mol}$ liq, 194, 13-19.

Sheremet, M. A., \& Pop, I. (2014). Conjugate natural convection in a square porous cavity filled by a nanofluid using Buongiorno's mathematical model. Int. J Heat and Mass Transfer, 79, 137-145.

Sheremet, M. A., Grosan, T., \& Pop, I. (2015). Free convection in a square cavity filled with a porous medium saturated by nanofluid using Tiwari and Das' nanofluid model. Transp Porous Media, 106, 595-610.

Srikanth, AK. (1969) Slip flow through long circular tubes Proc. Sixth Int. Symposium on Rarefied gas dynamics. Academic Press. 667-680.

Turkyilmazoglu, M. (2012). Exact analytical solutions for heat and mass transfer of MHD slip flow in nanofluids. Chemical Engineering Science, 84, 182-187.

Turkyilmazoglu, M. (2013). Heat and mass transfer of MHD second-order slip flow. Computers and Fluids, 71, 426-434.

Vajravelu, K., Prasad, K. V., Lee, J., Lee, C., Pop, I., \& Van Gorder, R. A. (2011). Convective heat transfer in the flow of viscous Ag-water and Cu-water nanofluids over a stretching surface. International Journal of Thermal Sciences, $50,843-851$.

Vishnu Ganesh, N., Ganga, B., \& Abdul Hakeem, A. K. (2014). Lie symmetry group analysis of magnetic field effects on free convective flow of a nanofluid over a semi infinite stretching sheet. J. Egyptian Math. Soc., 22, 304-310.

Vishnu Ganesh, N., Abdul Hakeem, A. K., Jayaprakash, R., \& Ganga, B. (2014). Analytical and numerical studies on hydromagnetic flow of water based metal nanofuids over a stretching sheet with thermal radiation effect. J Nanofluids, 3, 154-161.

Wang, C. Y. (1989). Free convection on a vertical stretching surface. J. Appl. Math. Mech. (ZAMM), 69, 418-420.

Wang, C. Y. (2009). Analysis of viscous flow due to a stretching sheet with surface slip and suction. Nonlinear Analysis: Real World Applications, 10, 375-380.

Wang, X. Q., \& Mujumdar, A. S. (2008a). A review on nanofluids. Part I: theoretical and numerical investigations. Brazilian Journal of Chemical Engineering, $25,613-630$

Wang, X. Q., \& Mujumdar, A. S. (2008b). A review on nanofluids. Part II: experiments and applications. Brazilian Journal of Chemical Engineering, $25,631-648$

Wu, L. A. (2008). A slip model for rarefied gas flows at arbitrary Knudsen number. Applied Physics Letters, 93, 253103.

Zaimi, K., Ishak, A., \& Pop, I. (2014). Flow past a permeable stretching/shrinking sheet in a nanofluid using two-phase model. PLOS ONE, 9, e111743. 